\title{
Knowledge on Cervical Cancer among Undergraduate University Students
}

\author{
Most. Luthfa Begum \\ Clinical Instructor, Enam Nursing College Savar, Dhaka, Bangladesh
}

DOI: $10.36348 /$ sjnhc.2020.v03i11.010

| Received: 09.11.2020 | Accepted: 22.11.2020 | Published: 25.11.2020

*Corresponding author: Most. Luthfa Begum

\section{Abstract}

Cervical cancer is a typically slow-growing cancer that may not have symptoms, but can be early diagnosed by Pap smear and Visual Inspection of Cervix with Acetic Acid (VIA). According to WHO and UNPF, globally every year, around 500,000 women develop cervical cancer and almost 274,000 of them die from the disease. Participants in this study did not report engaging in risk factors associated with cervical cancer, they had poor knowledge of etiology, mode of transmission, symptoms, prevention methods, and different risk factors that increase the progression of cervical cancer as well as poor perception towards the chance of acquiring the disease. Using TV and Radio and having information on STI were the determinants of knowledge on cervical cancer. The result obtained in this study indicates how useful it established health education programs to increase students' awareness and knowledge about cervical cancer. Health education interventions require improving the understanding of the factors that increases the risk and the prevention methods of cervical cancer in youth women to prevent before women engage in risky behaviors to develop healthy behavior and decrease the incidence of the disease. Governments and non-governmental organizations should work in collaboration in improving knowledge of cervical cancer and screening among youth women. For the reasons said above, this study was conducted among the tertiary level students at Gono Bishwabidyalay, Savar, Dhaka, Bangladesh.

Keywords: Knowledge, Cervical Cancer, Undergraduate Students, Public Health, and socio-demographic factors.

Copyright ( $) 2020$ The Author(s): This is an open-access article distributed under the terms of the Creative Commons Attribution 4.0 International License (CC BY-NC 4.0) which permits unrestricted use, distribution, and reproduction in any medium for non-commercial use provided the original author and source are credited.

\section{BACKGROUND OF THE STUDY}

Cervical cancer is a typically slow-growing cancer that may not have symptoms, but can be early diagnosed by Pap smear and Visual Inspection of Cervix with Acetic Acid (VIA). The burden of the disease is increasing in developing countries day by day due to the ascending trend of transmissible diseases such as HIV and Human Papilloma Virus (HPV) [1]. It is a serious burden on the reproductive health of women world-wide, despite the fact that it is preventable. Cervical cancer globally is the second most common cause of cancer-related deaths among adult women [2]. According to WHO and UNPF, globally every year, around 500,000 women develop cervical cancer and almost 274,000 of them die from the disease [3]. There are contributory factors that make women vulnerable to develop cervical cancer, viral infections (HPV, HIV, and HSV), multiparty, early initiation of sexual activity, multiple sex partners, smoking, low socioeconomic status, diet low in antioxidants, poor hygiene, long term use of oral contraceptives and immune suppression conditions[4-6].

\section{PROBLEM STATEMENT}

Cervical cancer is a preventable disease and a key aspect of prevention is early detection of precancerous conditions through the Papanicolaou cytology screening (Pap smear), it was accepted worldwide as an efficient tool for secondary prevention [7]. Pap smears effectively reduce the incidence of cervical cancer by $75-90 \%$. Disparity in incidence between the low- medium and high-income countries can be attributed to lack of awareness of cervical cancer and the lack of eff ective cytological screening programmes $[8,9]$.

According to WHO, Currently, two HPV vaccines (Gardasil 17 and Cervarix $\AA$ ) were approved for primary prevention of cervical cancer vaccine and both seem to protect against HPV6/11/16/18 and the HPV 16/18 respectively. The vaccines are recommended for young women before an HPV infection is acquired as well as before they begin their sexual intercourse [10, 11]. Many studies have been done in our country regarding cervical cancer, which was both hospital-based and community-based [12]. The aim of this study is to identify the level of knowledge and awareness of cervical cancer among 
undergraduate university students. Besides these, this study will also help to analyze a probable relationship between the overall knowledge level and a few sociodemographic parameters. The outcome measurement of this short study may provide inputs towards designing suitable Information, Education and Communication (IEC) strategies to inform and educate the women on cervical cancer and thus augment the national cancer control program.

\section{Justification}

Cervical cancer is the second most common cancer women suffer in Bangladesh. About 11,956 women are diagnosed with cervical cancer in the country every year and over 6,582 dies of the disease, according to a study of the International Agency for Research on Cancer (IARC) in 2017 which is indicating the need and importance of awareness program on the prevention of cervical cancer [13-15].

The primary reason for high incidence and deaths by cervical cancer has been identified as the absence of cervical cancer screening facilities, oncologists and health officials said Monday at a program for Dissemination of National Strategy for Cervical Cancer Prevention and Control in Bangladesh [16]. It is estimated that in Bangladesh, over 30 million women aged 30 to 60 need screening to find out whether or not they were suffering from cervical cancer [20]. As the prevalence of cervical cancer is increased day by day, it indicates the importance of knowledge and awareness on the prevention of cervical cancer. As a result, this study was conducted to identify the level of awareness of cervical cancer among undergraduate university students.

\section{Operational definition}

Knowledge - Knowledge is the fact or condition of knowing something with familiarity gained through experience or association. It can be defined as awareness or understanding of someone or something, such as facts, information, descriptions, or skills, which is acquired through experience or education by perceiving, discovering, or learning. Knowledge can refer to a theoretical or practical understanding of a subject. It can be implicit (as with practical skill or expertise) or explicit (as with the theoretical understanding of a subject); it can be more or less formal or systematic. (Oxford Dictionary)

Cervical Cancer - Cervical cancer is cancer arising from the cervix. It is due to the abnormal growth of cells that have the ability to invade or spread to other parts of the body. Early on, typically no symptoms are seen. Later symptoms may include abnormal vaginal bleeding, pelvic pain, or pain during sexual intercourse. While bleeding after sex may not be serious, it may also indicate the presence of cervical cancer. Human papillomavirus infection (HPV) causes more than $90 \%$ of cases; most people who have had HPV infections, however, do not develop cervical cancer. Other risk factors include smoking, a weak immune system, birth control pills, starting sex at a young age, and having many sexual partners, but these are less important. Cervical cancer typically develops from precancerous changes over 10 to 20 years. About $90 \%$ of cervical cancer cases are squamous cell carcinomas, $10 \%$ are adenocarcinoma and a small number are other types. Diagnosis is typically by cervical screening followed by a biopsy. Medical imaging is then done to determine whether or not cancer has spread. (Ref - The epidemiology of human papillomavirus infection and cervical cancer.

\section{List of Variables}

- Socio-demographic characteristics (Education, Residence, Age, Family income, Family size), Respondent's behavioral profile, Respondent's knowledge

- Level of knowledge on cervical cancer.

\section{Research Question}

What is the level of knowledge of cervical cancer among undergraduate university students?

\section{OBJECTIVES}

General Objective

- To identify the level of knowledge of cervical cancer among undergraduate university students.

\section{Specific objectives}

- To find out the socio-demographic characteristics of the respondents.

- To identify the respondent's knowledge level on etiology of cervical cancer.

- To assess student's knowledge on the mode of transmission of cervical cancer.

- To identify the respondent's knowledge level on symptoms of cervical cancer.

- To identify the respondent's knowledge of risk factors of cervical cancer.

- To determine the respondent's knowledge on the prevention of cervical cancer.

\section{RESEARCH METHODOLOGY Study Area} purposively.

One university (private) was selected

\section{Study Period \& Duration}

The study was conducted during the period from August 2019 to, November 2019.

\author{
Study Population \\ Undergraduate students of Gono \\ Bishwabidyalay
}


Study Design

Cross-sectional descriptive type of study

\section{Sample Size Estimation}

The following formula was used to calculate the sample size.

$$
\begin{aligned}
& \mathrm{n}=\mathrm{z}^{2} \mathrm{pq} / \mathrm{d}^{2} \\
& \text { Where } \mathrm{n}=\text { sample size } \\
& \mathrm{z}=1.96 \\
& \mathrm{p}=\text { Population proportion } 50 \%=0.5 \\
& \mathrm{q}=(1-\mathrm{p})=1-0.5=0.5 \\
& \mathrm{~d}=0.05
\end{aligned}
$$

(Papri FS, Khanam Z, Islam F, Hakim MM. Knowledge and awareness about risk factors of cervical cancer, its screening, and vaccination among the women attending Chittagong Medical College Hospital. Chattagram Maa-O-Shishu Hospital Medical College Journal. 2015 Nov 16;14(2):57-60.) So, $n=z^{2} p q / d^{2}$

$$
=\frac{1.96 \times 1.96 \times 0.5 \times 0.5}{0.05 \times 0.05} \approx 384
$$

So, the final sample size was 384 .

\section{Sampling Technique}

Systematic Sampling Technique

\section{Inclusion Criteria}

Undergraduate female students

\section{Exclusion Criteria} severely sick

Undergraduate female students who were

\section{Data Collection Method}

1. Data were collected by using a selfadministrative questionnaire.

2. The questionnaire consisted of all the necessary sections of questions that were needed to fulfill the objective of the study.

\section{Data Analysis Plan}

\begin{tabular}{|c|c|c|c|c|c|c|c|c|c|c|c|c|c|c|c|c|}
\hline \multirow{2}{*}{ Activities } & \multicolumn{4}{|c|}{ August } & \multicolumn{4}{|c|}{ September } & \multicolumn{4}{|c|}{ October } & \multicolumn{4}{|c|}{ November } \\
\hline & 1 & 2 & 3 & 4 & 1 & 2 & 3 & 4 & 1 & 2 & 3 & 4 & 1 & 2 & 3 & 4 \\
\hline Protocol develo & & & & & & & & & & & & & & & & \\
\hline Submission anc & & & & & & & & & & & & & & & & \\
\hline Literature revie & & & & & & & & & & & & & & & & \\
\hline $\begin{array}{l}\text { Development o } \\
\text { instrument }\end{array}$ & & & & & & & & & & & & & & & & \\
\hline $\begin{array}{l}\text { Pretesting of th } \\
\text { questionnaire }\end{array}$ & & & & & & & & & & & & & & & & \\
\hline Data collection & & & & & & & & & & & & & & & & \\
\hline Data entry and & & & & & & & & & & & & & & & & \\
\hline Data analysis & & & & & & & & & & & & & & & & \\
\hline Report writing & & & & & & & & & & & & & & & & \\
\hline
\end{tabular}

1. Data analysis were done by using Statistical Package for Social Science (SPSS) software Latest version.

2. Data were presented in the form of tables and charts.

\section{Time frame}

\section{Ethical Issues}

- The research was approved by the Research Ethics Committee of the Faculty of Allied Health Sciences of Daffodil International University, through the Department of Public Health.

- Administrative approval was taken by the university authority.

- Verbal informed consent was obtained from all the respondents

- $\quad$ Strict confidentiality was observed at all levels of the study process.

\section{Public Health Importance}

Cervical cancer is an insidious disease. It is the commonest cancer among women that may not have symptoms but can be found with regular Pap tests. At present, it is considered one of the major public health issues. The Government of Bangladesh (GOB) has developed a cervical cancer screening program through VIA. GOB has a plan to make it a nation-wide program. VIA is performed at Upazilla Health Complexes (UHC), Maternal and Child Welfare Centers (MCWCs), District Hospitals (DHs), Medical College Hospitals (MCHs), and in Bangabandhu Sheikh Mujib Medical 
University (BSMMU) by trained Family Welfare Visitors (FWVs), Senior Staff Nurses (SSNs) and doctors. Unlike developed countries, cervical cancer prevention programs have failed to meet their objectives in developing countries due to financial, social, and logistic shortcomings. Many studies have been done in our country regarding cervical cancer, which was both hospital-based and community-based. But this study will try to find out the knowledge, attitude, practice, awareness, and perception of women attending a private hospital. It will assess the awareness and knowledge of women about cervical cancer and cervical screening. The study will try to find out the status of the information about the disease, the rate of adoption of screening and vaccination, the barrier of screening, and vaccination from our perspective.

\section{LITERATURE REVIEW}

Cervical cancer is cancer arising from the cervix. It is due to the abnormal growth of cells that can invade or spread to other parts of the body. Early on, typically no symptoms are seen. Later symptoms may include abnormal vaginal bleeding, pelvic pain, or pain during sexual intercourse. While bleeding after sex may not be serious, it may also indicate the presence of cervical cancer. Human papillomavirus infection (HPV) causes more than $90 \%$ of cases; most people who have had HPV infections, however, do not develop cervical cancer. $^{22,23}$ Other risk factors include smoking, a weak immune system, birth control pills, starting sex at a young age, and having many sexual partners, but these are less important. Cervical cancer typically develops from precancerous changes over 10 to 20 years. About $90 \%$ of cervical cancer cases are squamous cell carcinomas, $10 \%$ are adenocarcinoma, and a small number are other types. Diagnosis is typically by cervical screening followed by a biopsy. ${ }^{24}$ Medical imaging is then done to determine whether or not cancer has spread. HPV vaccines protect against two to seven high-risk strains of this family of viruses and may prevent up to $90 \%$ of cervical cancers. As a risk of cancer still exists, guidelines recommend continuing regular Pap tests. Other methods of prevention include having few or no sexual partners and the use of condoms. Cervical cancer screening using the Pap test or acetic acid can identify precancerous changes, which when treated, can prevent the development of cancer. ${ }^{25-}$ 27 Treatment may consist of some combination of surgery, chemotherapy, and radiation therapy. Five-year survival rates in the United States are $68 \%$. Outcomes, however, depend very much on how early the cancer is detected. Worldwide, cervical cancer is both the fourth most common cause of cancer and the fourth most common cause of death from cancer in women. In 2012, an estimated 528,000 cases of cervical cancer occurred, with 266,000 deaths [28]. This is about $8 \%$ of the total cases and total deaths from cancer. About $70 \%$ of cervical cancers and $90 \%$ of deaths occur in developing countries. In low-income countries, it is one of the most common causes of cancer death. In developed countries, the widespread use of cervical screening programs has dramatically reduced rates of cervical cancer. In medical research, the most famous immortalized cell line, known as HeLa, was developed from cervical cancer cells of a woman named Henrietta Lacks [29-32].

Cervical cancer is a global public health problem with 527,624 new cases and 265,653 deaths annually, accounting for $9 \%$ of female cancer deaths. Eighty-three percent of new cases and more than $85 \%$ of related deaths are in low and middle-income countries. Eastern Africa has a higher proportion of cervical cancer burden than other regions in Africa and an HPV prevalence of 35.4 percent of women $\geq 15$. Ethiopia has a population of 27.19 million women aged 15 years and older who are at risk of developing cervical cancer [33]. Current estimates indicate that every year 7,095 women are diagnosed with cervical cancer and 4732 dies from the disease. Cervical cancer ranks as the 2nd most frequent cancer among women in Ethiopia and Cervical cancer is the 2nd leading cause of cancer deaths in women aged15 to 44years in Ethiopia. Cervical cancer is preventable and, in most cases, curable if identified in its early stages. Knowledge about early signs and symptoms is crucial for early diagnosis and treatment. Though preventable and curable, most women in developing countries including Ethiopia presents at an advanced stage that requires extensive treatment modalities like surgery, radiotherapy, chemotherapy and has a markedly diminished chance of success [34]. A study in Nigeria, Abiodun et al., showed that only $2.3 \%$ of the women could identify a virus as the cause of cervical cancer while $4.1 \%$ identified cervical screening as a way to prevent cervical cancer. Another study conducted in South Africa among female university students indicated that $15.6 \%$ did not know any risk factors for cervical cancer, $58.6 \%$ of 164 students who knew of risk factors, did not know that cervical cancer is preventable [35]. The Pap smear test used for detection or prevention of cervical cancer was known to only $38 \%$ of the respondents. The results of studies indicated that female university students are at a higher risk of STIs associated with cervical cancer such as Human Papilloma Virus (HPV) infections because of multiple lifetime sex partners and pass through education institutions without getting adequate knowledge about cervical cancer. In contrast to developing countries, experience in developed countries has shown that healthy lifestyles, such as health information and warnings about tobacco use, sexuality education tailored to age \& culture, condom promotion/provision for those engaged in sexual activity, vaccination against HPV, and well planned, organized screening programs with high coverage can significantly reduce the number of new cases of cervical cancer and the mortality rate associated with it [36]. Most studies conducted in Nigeria, Ethiopia, Bhutan, and Maldives among women of reproductive age groups indicated that the level of 
knowledge and perception about cervical cancer was very low. But studies regarding knowledge and perception of cervical cancer among young women in Ethiopia are very limited.

Organized cytology-based screening programs to achieve high coverage rates by using Papanicolaou smears and treatment of pre-cancerous lesions, has led to a significant decrease in cervical cancer incidence and mortality in developed countries [37]. These successes of the organized based screening have not been replicated in developing countries reflecting an enormous global-cervical-cancer burden of $83 \%$. The imbalances are alarming; developed countries have an average screening coverage of $63 \%$, compared to $19 \%$ in developing countries. The sub-Saharan African region, one of the most affected areas of cervical cancer has scarce access to only $5 \%$ of the global-cervical cancer-prevention resources. Besides, $85 \%$ of all cervical cancer-related deaths reported were from developing countries that have poor setups of screening programs or minimally effective. Screening is found to be the best method for early detection of cervical cancer. Cervical cancer is currently primary cancer amongst the women in South Africa, with annual new cases of 6742 in African women and 3681 deaths. HIVpositive women are 3 to 5 times more likely to develop cervical lesions that could become cancerous [38].

This makes a high-risk environment for the acquisition of cervical cancer in South Africa because about $13.3 \%$ of the female are living with HIV/AIDS. The incidence rate has doubled compared to that of global estimates at 30.2 per 100,000 women per year. During the year 2000, deaths related to cervical cancer in South Africa have exceeded that of maternal deaths. In SA, the cervical cancer screening coverage (proportion of women over the age of 30 years) is low e.g. $20 \%$ nationally. A population-based -study conducted in rural KwaZulu-Natal reported that $18 \%$ only of the women had a Pap smear test done. University students have a higher risk of acquiring sexually transmitted infections (STIs) than the general population because of the high-risk sexual behavior in which they engaged. Many university students underestimate their risk of contracting various STIs, and HPV has become a common sexually transmitted infection on college campuses. Risky sexual behavior, a lack of knowledge, and preventive care, such as a regular Pap test have led to a high incidence of HPV infection in university students. These lead to cervical cancer later [39].

Cervical cancer is the single largest killer of middle-aged women in India. The incidence of cervical cancer per 100, 000 Indian women of all ages varied between 30.0 and 44.9. India bears about one-fifth of the world's burden of cervical cancer. More than 100,000 new cases are detected in India per year and the disease causes almost 20 percent of all female deaths in India. About $75-80 \%$ of the cases are reported in the advanced stage [40]. The menace of cervical cancer is still haunting India in-spite of this being a preventable disease. The key to reducing cervical cancer morbidity and mortality is early detection and treatment of cervical precancerous lesions. A population-based screening program utilizing exfoliate cervical cytology, the Papanicolaou (Pap) test, has reduced cervical cancer morbidity and mortality in developed countries. Screening test for cervical infection of human papillomavirus (HPV), the primary cause of cervix cancer, has proved to be more effective. Recently developed prophylactic vaccines for HPV have the potential to protect new generations of girls. Despite being effective most of the women in developing and under-developed countries do not have access to Pap (Papanicolaou) smear screening [41]. In India also, both early detection and screening remain a major area of concern to the health workers in the absence of screening facilities coupled with poor literacy and low level of awareness amongst Indian women. This ultimately becomes a hindrance towards the formulation of an exhaustive policy to tackle the menace of cervical cancer. The success and benefit of a public health program to control and prevent cervical cancer will depend to a great extent on the level of awareness of the potential beneficiaries about different basic aspects of the disease. Various studies have been undertaken to assess women's awareness and knowledge level about cervical cancer. However, currently, scanty information is available on the knowledge base of the Indian women on cancer of the uterine cervix [31].

Women in Sub-Saharan Africa are worst hit with $\mathrm{CC}$; here, it is the most common cancer responsible for $13 \%$ of all female cancers. In Nigeria, it is the second most common female cancer after breast cancer. It is the most common female genital cancer responsible for most mortality cases among Nigerian females during their most productive years. It has become incontrovertible that $\mathrm{CC}$ screening lowers the risk of $\mathrm{CC}$ and its resultant mortality. A risk modifying effect of almost $80 \%$ reduction has been demonstrated through regular screening [32]. CC screening uptake is also modulated by the knowledge base of women; the lower the knowledge of women about CC and ways of preventing it, the less likely these women will embrace the screening services. In 2007, it was reported that 36.59 million women aged $\geq 15$ years in Nigeria were at risk of developing cervical cancer. There are 9922 cases diagnosed annually with 8030 deaths. In many developed countries, where national routine screening programs using the Papanicolaou (Pap) smear have been implemented, the $\mathrm{CC}$ incidence and mortality have been significantly reduced. Early detection and treatment of cervical precancerous lesions are associated with high cure rates, whereas failure to detect precancerous lesions increases the risk to $\mathrm{CC}$ 
development and hence the risk of premature death [3437].

Cervical cancer has been determined to be the fourth most frequently observed cancer type with 528,000 new cases and 266,000 deaths expected in females in 2012. Cervical cancer is an important health problem in the world; its incidence and mortality rate is reported to be $7.9 \%$ and $7.5 \%$, respectively. The prevalence of cancer in Turkey and Poland is similar to that in other developing countries and each other. In Turkey, breast cancer is in the first place with 45.1 incidences per one hundred thousand, and cervical cancer is in ninth place with 7.1 incidences per one hundred thousand. The incidences of breast cancer and cervical cancer in Poland have been reported to be 69.9 and 15.3 per one hundred thousand, respectively. Early diagnosis of cancer is important in terms of effective treatment of the disease and an extended life span. Cancer screenings consist of examinations and reviews carried out on healthy individuals while there are no symptoms or indications, to facilitate early diagnosis. Breast and cervical cancer are the most frequently observed types of cancer in females, and early diagnoses can successfully be made $[39,40]$.

Approximately $80 \%$ of cervical cancers occur in developing countries. Worldwide, cervical cancer is the 12th most common cause and 5th most deadly cancer in women. In Bangladesh, genital cancer is increasing day by day. Unfortunately, there are few population-based data about its magnitude. Among those, cervical cancer constitutes about 22-29\% (from hospital-based data) throughout the country. The yearly burden of cervical cancer is about 17,686 and around 10,364 women die from cervical cancer each year. Bangladesh is a developing country with limited resources. The Government of Bangladesh (GOB) has developed a cervical cancer screening program through VIA. GOB has a plan to make it a nation-wide program. VIA is performed at Upazilla Health Complexes (UHC), Maternal and Child Welfare Centers (MCWCs), District Hospitals (DHs), Medical College Hospitals (MCHs), and in Bangabandhu Sheikh Mujib Medical University (BSMMU) by trained Family Welfare Visitors (FWVs), Senior Staff Nurses (SSNs) and doctors. The services for cervical and breast cancer screening are currently available as opportunistic screening at 252 facilities including BSMMU, 14 MCHs, 57 DHs, 61 MCWCs, 15 (out of 482) UHC, 44 (out of 3725) Union Health \& Family Welfare Centers (UH\&FWC), 25 Urban Primary Health Care Centers and 35 Non-Government Organizations (NGO). The trained manpower uses the VIA technique to detect the pre-cancer or early stages of cervical cancer among women of 30 years and above visiting the aforementioned centers [41]. VIA positive women are referred to BSMMU and various government $\mathrm{MCH}$ for colposcopy evaluation and necessary management. This service is technically and financially supported by
GOB, BSMMU, and UNFPA. During the last five years, only three lac women have received screening services. During the evaluation of the 'Cervical Cancer Screening Program of Bangladesh' low coverage of the target population was observed. Lack of awareness about cervical cancer and its prevention, low availability of services may be underlying factors for this low intake of services. It was observed that the uptake of screening in developing countries is poor. Lack of awareness of cervical cancer has been identified as one of the factors contributing to the high prevalence of this condition in the developing world compared to the developed world. Unlike developed countries, cervical cancer prevention programs have failed to meet their objectives in developing countries due to financial, social, and logistic shortcomings [21].

According to the International Agency for Research on Cancer (IARC), India has the highest number of cervical cancer cases in the world. There are an estimated 1, 32,000 new cases and 74,000 deaths each year which occur due to cervical cancer in India. Sexually transmitted infection with human papillomavirus (HPV) is fundamental to the development of carcinoma of the cervix. HPV prevalence increases with multiple sexual partners and poor genital hygiene. Of the $100 \mathrm{HPV}$ types, 18 have been categorized as high-risk types for cervical cancer, while the rest are low-risk types. Cervarix $\hat{A} \AA$ made by Glaxo SmithKline (GSK) is a bivalent vaccine that protects against HPV strains 16 and 18, and GardasilÂß by Merck is a quadrivalent vaccine that protects the individual against HPV strains 16, 18, 6, and 11[22]. These two types of vaccine are available for use by the community with private health care providers. However, there is no provision for the HPV vaccine at the institute where the study has been carried out. HPV types 16 and 18 are said to account for approximately $70 \%$ of all cervical cancer cases in India. The Program for Appropriate Technology in Health (PATH), a USA-based not for profit non-governmental organization (NGO), has been undertaking postlicensing observational studies on HPV vaccines in India on coverage, acceptability, feasibility, and costs of the vaccines in two Indian states, Gujarat and Andhra Pradesh, funded by the Bill \& Melinda Gates Foundation. The study was suspended in April 2010 by the Government of India amid public concerns about safety. Currently, PATH and the Indian government are investigating whether to implement an HPV vaccination program. Cervical cancer is a deadly disease once it reaches the invasive stages, but out of all the female genital tract cancers, it is the only preventable cancer if detected at its early stages [25]. Population-based screening with Pap smear is an important secondary preventive measure for cervical cancer that leads to a high-cure rate among cervical cancer patients. The facilities to carry out Pap smear are available in the institute where the study has been carried out. Also, under the National Cancer Control Program, screening 
camps for early detection of cervical cancer are organized in various regions of Gujarat at regular intervals by the Gujarat Cancer Research Institute which is one of the regional cancer care institutes of India. A recent qualitative study reported a low level of knowledge on HPV and cervical cancer among children, parents, teachers, community leaders, and even health service providers of four developing countries (India, Peru, Uganda, and Vietnam). Very similar results, i.e. lack of proper knowledge regarding cervical cancer were found in several studies conducted in other countries in the world. Nurses can provide health promotion counseling to the patients they serve in their day-to-day practice. They can fulfill a key role in health promotion and disease prevention, and they are in an ideal position to provide health education to young girls and women. It is necessary to make the nursing staff aware of cervical cancer, who can impart knowledge regarding cervical cancer and its prevention to the general public [26].

World Health Organization statistics show that India carries one-fifth of the world's burden of the disease with 67,000 deaths annually. Human Papilloma Virus (HPV) predominantly HPV 16 and HPV 18 are known causative agents of cervical cancer in $70 \%$ of the cases. The virus infects the squamous epithelium of the cervix leading to precancerous, cervical intraepithelial lesions and subsequently to invasive cancer. The introduction of the Papanicolaou test by George Papanicolaou along with the advent of preventive vaccination against HPV has revolutionized early detection and prevention of cervical cancers. However, it is appalling to note that the proportion of women screened ranges from about $84 \%$ in developed countries to $5 \%$ in developing nations like India. Key to the success of cervical cancer screening and prevention is the knowledge and awareness possessed by women in general [12].

There are contributory factors that make women vulnerable to develop cervical cancer, viral infections (HPV, HIV, and HSV), multi-parity, early initiation of sexual activity, multiple sex partners, smoking, low socioeconomic status, a diet low in antioxidants, poor hygiene, long term use of oral contraceptives and immune suppression conditions. Cervical cancer is a preventable disease and a key aspect of prevention is early detection of precancerous conditions through the Papanicolaou cytology screening (Pap smear), it was accepted worldwide as an efficient tool for secondary prevention. Pap smears effectively reduce the incidence of cervical cancer by $75-90 \%$. The disparity in incidence between the low- medium and high-income countries can be attributed to a lack of awareness of cervical cancer and the lack of effective cytological screening programs. Currently, two HPV vaccines (Gardasil 17 and Cervarix $®$ ) were approved for primary prevention of cervical cancer vaccine and both seem to protect against HPV6/11/16/18 and the
HPV 16/18 respectively. The vaccines are recommended for young women before an HPV infection is acquired as well as before they begin their sexual intercourse. Strategies were developed to advocate for visual inspection with acetic acid (VIA) and visual inspection with Lugol's iodine (VILI) tests as alternative strategies. These trials are largely used in developing countries since they are fewer laboratories dependent, and a range of healthcare providers such as a physician, nurses, midwives, and paramedical health workers can be trained in 5-10 days compared with the training of cytotechnologists that required 12-24 months for cytology screening [14-17].

Findings

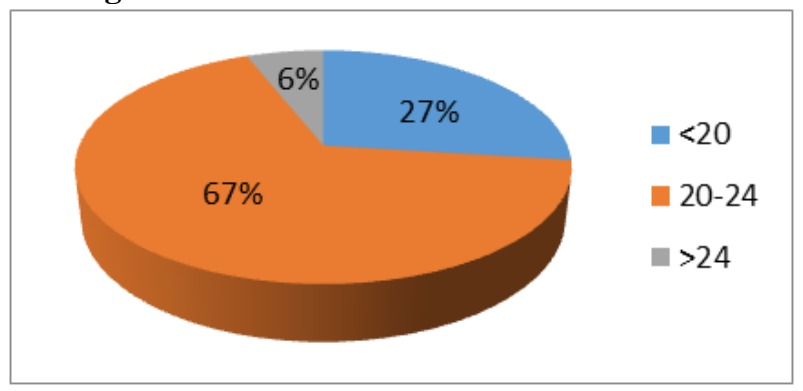

Fig-01: Distribution of respondents according to their age

Figure 01 shows the distribution of respondents according to their age. The findings show that $67 \%$ of respondents belonged to the age group of 20 to 24 years. $27 \%$ of respondents were below 20 and the rest $6 \%$ of respondents were aged more than 24 years.

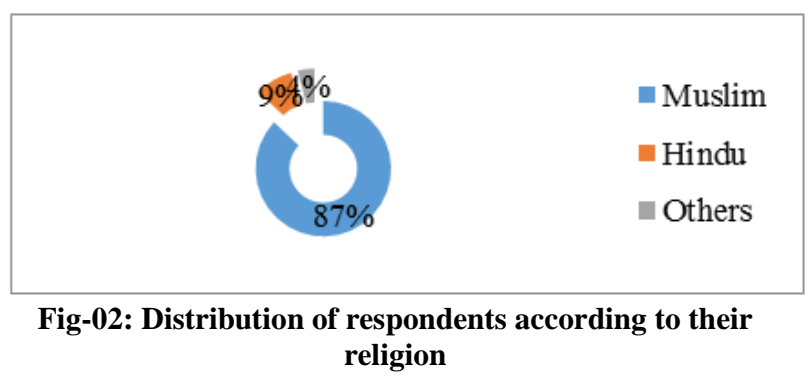

Figure 02 shows the distribution of respondents according to their religion. Findings show that $87 \%$ of respondents were Muslim, 9\% of respondents were the follower of Hinduism whereas the rest $4 \%$ of respondents belonged to other religions.

Table-01: Distribution of respondents according to their study year

\begin{tabular}{|c|c|c|}
\hline Study year & No. of students & Percentage \\
\hline $1^{\text {st }}$ year & 142 & 37 \\
\hline $2^{\text {nd }}$ year & 96 & 25 \\
\hline $3^{\text {rd }}$ year & 65 & 17 \\
\hline $4^{\text {th }}$ year & 81 & 21 \\
\hline Total & 384 & 100 \\
\hline
\end{tabular}


Table 01 shows the distribution of respondents according to their study year. The findings show that, among all the respondents, $37 \%$ belonged to $1^{\text {st }}$ year, $25 \%$ were studied in the $2^{\text {nd }}$ year, $17 \%$ were in $3^{\text {rd }}$ year, and the rest $21 \%$ of students were in $4^{\text {th }}$ or final year of their graduation.

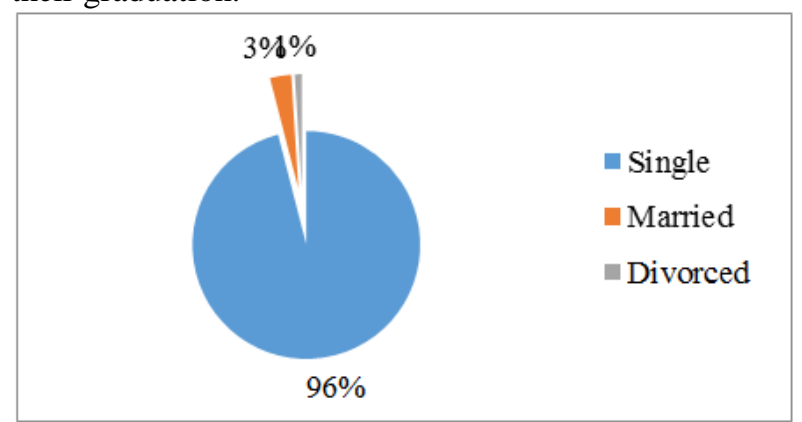

Fig-03: Distribution of respondents according to their marital status

Figure 03 shows the distribution of respondents according to their marital status. The findings show that $96 \%$ of respondents were single, $3 \%$ were married and only $1 \%$ of respondents were divorced.

Table-02: Distribution of the respondent's according to their monthly income/pocket money

\begin{tabular}{|c|c|c|}
\hline Monthly income (Tk.) & Frequency & Percentage \\
\hline$<5000$ & 92 & 24 \\
\hline $5000-7000$ & 108 & 28 \\
\hline $7000-10000$ & 146 & 38 \\
\hline$>10000$ & 38 & 10 \\
\hline Total & 384 & 100 \\
\hline
\end{tabular}

Table 02 shows the distribution of the respondent's monthly income/pocket money. The findings show that $24 \%$ of respondent's monthly income/pocket money was less than 5000, $28 \%$ of respondent's monthly income/pocket money was in between 5000 to $7000,38 \%$ of respondent's monthly income/pocket money was in between 7000 to 10000 and rest $10 \%$ respondent's monthly income/pocket money was more than 10000 BDT.

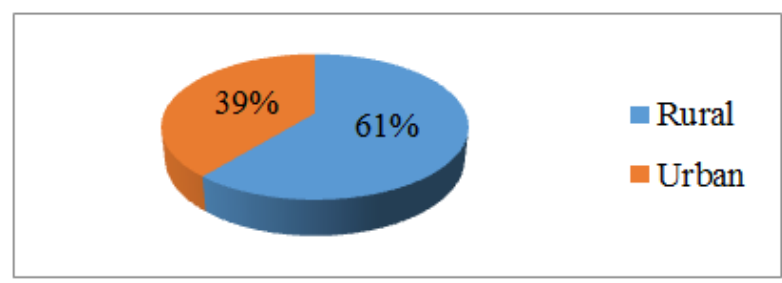

Fig-04: Distribution of respondents according to their residence area

Figure 04 shows the distribution of respondents according to their residence area. The findings show that $61 \%$ of respondents were from rural areas and the remaining $39 \%$ of respondents were from an urban area.
Table-03: Distribution of respondents on ever hearing about cervical cancer

\begin{tabular}{|c|c|c|}
\hline $\begin{array}{c}\text { Information on } \\
\text { CC }\end{array}$ & $\begin{array}{c}\text { No. of } \\
\text { respondents }\end{array}$ & Percentage \\
\hline Ever heard & 131 & 34 \\
\hline Never heard & 253 & 66 \\
\hline Total & 384 & 100 \\
\hline
\end{tabular}

Table 03 shows the distribution of respondents on ever hearing about cervical cancer. The findings show that among 384 respondents, only $34 \%$ of respondents have ever heard about cervical cancer whereas $66 \%$ of the respondents never heard about it.

Table-04: Distribution of respondent's knowledge on the etiology of cervical cancer

\begin{tabular}{|c|c|c|c|c|}
\hline \multirow{2}{*}{$\begin{array}{c}\text { Etiology of cervical } \\
\text { cancer }\end{array}$} & \multicolumn{2}{|c|}{$\begin{array}{c}\text { No. of } \\
\text { respondents }\end{array}$} & \multicolumn{2}{c|}{ Percentage } \\
\cline { 2 - 5 } & Yes & No & Yes & No \\
\hline HIV & 7 & 124 & $5 \%$ & $95 \%$ \\
\hline HPV & 20 & 111 & $15 \%$ & $85 \%$ \\
\hline Genetics & 4 & 127 & $3 \%$ & $97 \%$ \\
\hline Don't know & 101 & 30 & $77 \%$ & $23 \%$ \\
\hline
\end{tabular}

Table 04 shows the distribution of respondent's knowledge of the etiology of cervical cancer. The findings show that $5 \%$ of respondents thought that the cause of cervical cancer is HIV, $15 \%$ of respondents thought that HPV is the cause of cervical cancer, $3 \%$ thought that genetics is the main reason for $\mathrm{CC}$ whereas the remaining $77 \%$ of respondents did not know the cause of cervical cancer.

Table-05: Distribution of respondent's knowledge on the mode of transmission of cervical cancer

\begin{tabular}{|c|c|c|c|c|}
\hline \multirow{2}{*}{$\begin{array}{c}\text { Mode of } \\
\text { transmission }\end{array}$} & \multicolumn{2}{|c|}{$\begin{array}{c}\text { No. of } \\
\text { respondents }\end{array}$} & \multicolumn{2}{c|}{ Percentage } \\
\cline { 2 - 5 } & Yes & No & Yes & No \\
\hline Mother to child & 10 & 121 & $8 \%$ & $92 \%$ \\
\hline Family history & 9 & 122 & $7 \%$ & $93 \%$ \\
\hline Sexual intercourse & 42 & 89 & $32 \%$ & $68 \%$ \\
\hline $\begin{array}{c}\text { Could not } \\
\text { transmitted }\end{array}$ & 18 & 113 & $14 \%$ & $86 \%$ \\
\hline Do not know & 51 & 80 & $39 \%$ & $61 \%$ \\
\hline
\end{tabular}

Table 05 shows the distribution of respondent's knowledge on the mode of transmission of cervical cancer. The findings show that $8 \%$ of respondents responded that the mode of transmission of cervical cancer is mother to child, $7 \%$ told that family history is responsible for the transmission of cervical cancer, $32 \%$ responded that sexual intercourse is the mode of transmission of cervical cancer, $14 \%$ expressed that cervical cancer cannot be transmitted and $39 \%$ do not know about the mode of transmission. 
Table-06: Distribution of respondent's knowledge about the symptoms of cervical cancer

\begin{tabular}{|c|c|c|c|c|}
\hline \multirow{2}{*}{ Symptoms of cervical cancer } & \multicolumn{2}{|c|}{ No. of respondents } & \multicolumn{2}{c|}{ Percentage } \\
\cline { 2 - 5 } & Yes & No & Yes & No \\
\hline Foul vaginal discharge & 34 & 97 & $26 \%$ & $74 \%$ \\
\hline Pain during sexual intercourse & 25 & 106 & $19 \%$ & $81 \%$ \\
\hline Bleeding during or after sexual intercourse & 7 & 124 & $5 \%$ & $95 \%$ \\
\hline Post-menopausal bleeding & 4 & 127 & $3 \%$ & $97 \%$ \\
\hline Inter-menstrual bleeding & 1 & 130 & $1 \%$ & $99 \%$ \\
\hline Itching & 3 & 128 & $2 \%$ & $98 \%$ \\
\hline Don't know & 58 & 73 & $44 \%$ & $56 \%$ \\
\hline
\end{tabular}

Table 06 shows the distribution of respondent's knowledge about the symptoms of cervical cancer. 26\% responded that foul vaginal discharge is the main symptom of cervical cancer, $19 \%$ respondents told that pain during sexual intercourse is the symptom of cervical cancer, $5 \%$ told that bleeding during or after sexual intercourse is the symptom of cervical cancer,
$3 \%$ said that post-menopausal bleeding is the symptom of cervical cancer, $1 \%$ responded that inter-menstrual bleeding is the symptom of cervical cancer, $2 \%$ told that itching is the symptom of cervical cancer and rest $44 \%$ respondents didn't know anything about the symptom of cervical cancer.

Table-07: Distribution of respondent's knowledge about the risk factors of cervical cancer

\begin{tabular}{|c|c|c|c|c|}
\hline \multirow{2}{*}{ Risk factors of cervical cancer } & \multicolumn{2}{|c|}{ No. of respondents } & \multicolumn{2}{c|}{ Percentage } \\
\cline { 2 - 5 } & Yes & No & Yes & No \\
\hline Having many partners & 34 & 97 & $26 \%$ & $74 \%$ \\
\hline Early sexual debut & 9 & 122 & $7 \%$ & $93 \%$ \\
\hline Husband's polygamy & 12 & 119 & $9 \%$ & $91 \%$ \\
\hline HIV and other STIs & 4 & 127 & $3 \%$ & $97 \%$ \\
\hline Tobacco & 8 & 123 & $6 \%$ & $94 \%$ \\
\hline Long time use of pills & 18 & 113 & $14 \%$ & $86 \%$ \\
\hline Multiparty & 1 & 130 & $1 \%$ & $99 \%$ \\
\hline Do not know & 45 & 86 & $34 \%$ & $66 \%$ \\
\hline
\end{tabular}

Table 07 shows the distribution of respondent's knowledge about the risk factors of cervical cancer. Among all the respondents $26 \%$ responded that the risk factor of cervical cancer is having many partners, $7 \%$ told that that the risk factor of cervical cancer in the early sexual debut, $9 \%$ of respondents told that husband's polygamy is the risk factor of cervical cancer, 3\% respondents responded that HIV and other STIs are the risk factors of cervical cancer, $6 \%$ participants responded that tobacco is the risk factors of cervical cancer, $14 \%$ respondents told that long time use of pills is the risk factors of cervical cancer, $1 \%$ respondent told that multiparty is the risk factor of cervical cancer and the rest $34 \%$ respondents did not know about the risk factor of cervical cancer.

Table-08: Distribution of respondent's knowledge about the prevention methods of cervical cancer

\begin{tabular}{|c|c|c|c|c|}
\hline \multirow[t]{2}{*}{ Prevention methods for cervical cancer } & \multicolumn{2}{|c|}{ No. of respondents } & \multicolumn{2}{|c|}{ Percentage } \\
\hline & Yes & No & Yes & No \\
\hline Could not prevent & 8 & 123 & $6 \%$ & $94 \%$ \\
\hline Screening & 30 & 101 & $23 \%$ & $77 \%$ \\
\hline Vaccination & 17 & 114 & $13 \%$ & $87 \%$ \\
\hline Delay early sexual debut & 21 & 110 & $16 \%$ & $84 \%$ \\
\hline Avoid having multiple partners & 9 & 122 & $7 \%$ & $93 \%$ \\
\hline Limit number of children & 5 & 126 & $4 \%$ & $96 \%$ \\
\hline Avoid tobacco & 3 & 128 & $2 \%$ & $98 \%$ \\
\hline Do not know & 38 & 93 & $29 \%$ & $71 \%$ \\
\hline
\end{tabular}

Table 08 shows the distribution of respondent's knowledge about the prevention methods of CC. the findings show that $6 \%$ of respondents told that cervical cancer cannot be prevented, $23 \%$ told that it can be prevented by screening, $13 \%$ told that vaccination is the method of preventing CC, $16 \%$ responded that delay early sexual debut helps prevent cervical cancer, $7 \%$ told that avoiding having multipartner helps prevent cervical cancer, $4 \%$ responded that limiting the number of children can be helpful for prevention of cervical cancer, $2 \%$ told that avoiding tobacco can help prevent cervical cancer and the rest $29 \%$ said that they didn't know the prevention methods of cervical cancer. 


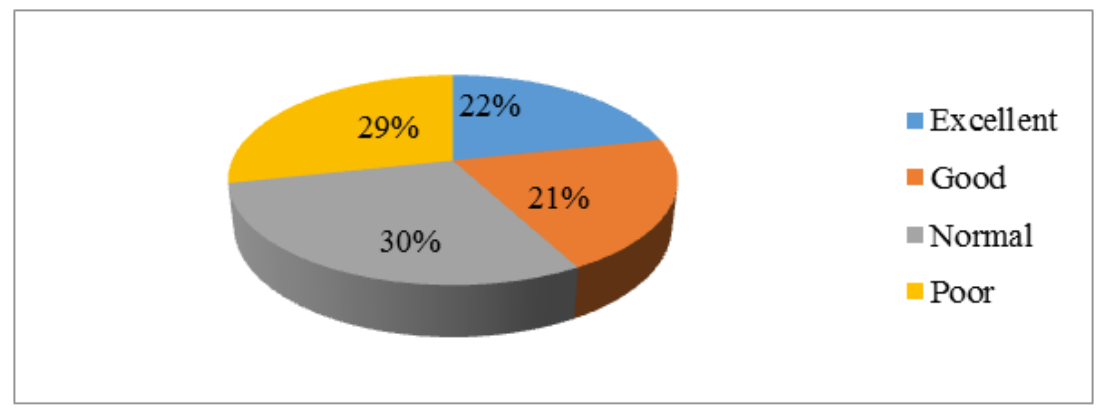

Fig-05: Distribution of respondent's knowledge score

Figure 05 shows the distribution of respondent's knowledge scores. Participant's knowledge about cervical cancer was assessed by using a 20 points scale of questions about the etiology, mode of transmission, symptoms, risk factors, and prevention methods. A knowledge score was calculated for each participant based on the number of questions correctly answered in the knowledge section. A score of 1 was assigned to every correct answer and a score of zero to incorrect responses. Knowledge questions were scored and pulled together and the mean score was computed to determine the overall knowledge of the participants. Participants who scored above the mean were considered as having good knowledge and below average as having poor knowledge. The findings show that among the entire respondents $22 \%$ respondent's knowledge score was excellent, $21 \%$ respondent's score was good, 30\% respondent's score was normal and 29\% respondent's knowledge level was poor.

Table-09: Association between socio-demographic factors and knowledge of cervical cancer among undergraduate university students

\begin{tabular}{|c|c|c|c|c|c|c|}
\hline \multirow{2}{*}{ Variable } & \multirow{2}{*}{ Category } & \multicolumn{3}{|c|}{ Knowledge of cervical cancer } & \multirow{2}{*}{ P-value } \\
\cline { 3 - 6 } & & Excellent (29) & Good (28) & Normal (39) & Poor (38) & \\
\hline \multirow{3}{*}{ Age } & $<20$ & $21 \%$ & $31 \%$ & $26 \%$ & $30 \%$ & \\
& $20-24$ & $72 \%$ & $62 \%$ & $42 \%$ & $41 \%$ & 0.065 \\
& $\geq 25$ & $7 \%$ & $7 \%$ & $32 \%$ & $29 \%$ & \\
\hline \multirow{5}{*}{ Year of study } & $1^{\text {st }}$ year & $36 \%$ & $33 \%$ & $12 \%$ & $31 \%$ & \\
& $2^{\text {nd }}$ year & $22 \%$ & $17 \%$ & $37 \%$ & $20 \%$ & 0.002 \\
& $3^{\text {rd }}$ year & $31 \%$ & $27 \%$ & $21 \%$ & $37 \%$ & \\
& $4^{\text {th year }}$ & $11 \%$ & $23 \%$ & $30 \%$ & $12 \%$ & \\
\hline \multirow{3}{*}{ Marital status } & Single & $92 \%$ & $97 \%$ & $90 \%$ & $87 \%$ & \\
& Married & $6 \%$ & $2 \%$ & $6 \%$ & $7 \%$ & 0.365 \\
& Divorced & $2 \%$ & $1 \%$ & $4 \%$ & $6 \%$ & \\
\hline
\end{tabular}

Table 10 shows the association between sociodemographic factors and knowledge of cervical cancer among undergraduate university students. The findings show that the respondent's years of study are significantly co-related with the knowledge level of the respondents regarding cervical cancer. The findings also show that the respondent's age and marital status have no significant association with the knowledge level of the respondents regarding cervical cancer.

\section{DISCUSSION}

The findings of this study show that $67 \%$ of respondents belonged to the age group of 20 to 24 years. $27 \%$ of respondents were below 20 and the rest $6 \%$ of respondents were aged more than 24 years. The distribution of respondents according to their religion show that $87 \%$ of respondents were Muslim, $9 \%$ of respondents were the follower of Hinduism whereas the rest $4 \%$ of respondents belonged to other religions. Among all the respondents, $37 \%$ belonged to the $1^{\text {st }}$ year, $25 \%$ were studied in the $2^{\text {nd }}$ year, $17 \%$ were in the $3^{\text {rd }}$ year, and the rest $21 \%$ students were in the $4^{\text {th }}$ or final year of their graduation. $96 \%$ of respondents were single, $3 \%$ were married and only $1 \%$ of respondents were divorced. The distribution of the respondent's monthly income/pocket money show that $24 \%$ of respondent's monthly income/pocket money was less than $5000,28 \%$ of respondent's monthly income/pocket money was between 5000 to $7000,38 \%$ of respondent's monthly income/pocket money was in between 7000 to 10000 and rest $10 \%$ respondent's monthly income/pocket money was more than 10000 BDT. $61 \%$ of respondents were from a rural area and the remaining $39 \%$ of respondents were from an urban area. Among 384 respondents, only $34 \%$ of respondents have ever heard about cervical cancer whereas $66 \%$ of the respondents never heard about it.

Among all the respondents, 5\% of respondents thought that the cause of cervical cancer is HIV, $15 \%$ of respondents thought that HPV is the cause of cervical cancer, $3 \%$ thought that genetics is the main reason for cervical cancer whereas the remaining $77 \%$ respondents did not know the cause of cervical cancer. The 
distribution of respondent's knowledge on the mode of transmission of cervical cancer shows that $8 \%$ of respondents responded that the mode of transmission of cervical cancer is mother to child, $7 \%$ told that family history is responsible for the transmission of cervical cancer, $32 \%$ responded that sexual intercourse is the mode of transmission of cervical cancer, $14 \%$ expressed that cervical cancer cannot be transmitted and $39 \%$ do not know about the mode of transmission. $26 \%$ responded that foul vaginal discharge is the main symptom of cervical cancer, $19 \%$ respondents told that pain during sexual intercourse is the symptom of cervical cancer, $5 \%$ told that bleeding during or after sexual intercourse is the symptom of cervical cancer, $3 \%$ said that post-menopausal bleeding is the symptom of cervical cancer, $1 \%$ responded that inter-menstrual bleeding is the symptom of cervical cancer, $2 \%$ told that itching is the symptom of cervical cancer and rest $44 \%$ respondents didn't know anything about the symptom of cervical cancer.

Among all the respondents $26 \%$ responded that the risk factor of cervical cancer is having many partners, $7 \%$ told that that the risk factor of cervical cancer in the early sexual debut, $9 \%$ of respondents told that husband's polygamy is the risk factor of cervical cancer, $3 \%$ respondents responded that HIV and other STIs are the risk factors of cervical cancer, $6 \%$ participants responded that tobacco is the risk factors of cervical cancer, $14 \%$ respondents told that long time use of pills is the risk factors of cervical cancer, $1 \%$ respondent told that multiparty is the risk factor of cervical cancer and the rest $34 \%$ respondents did not know about the risk factor of cervical cancer.

Participant's knowledge about cervical cancer was assessed by using a 20 points scale of questions about the etiology, mode of transmission, symptoms, risk factors, and prevention methods. A knowledge score was calculated for each participant based on the number of questions correctly answered in the knowledge section. A score of 1 was assigned to every correct answer and a score of zero to incorrect responses. Knowledge questions were scored and pulled together and the mean score was computed to determine the overall knowledge of the participants. Participants who scored above the mean were considered as having good knowledge and below average as having poor knowledge. The findings show that among all the respondents $41 \%$ of respondent's knowledge score was good and 59\% of respondent's knowledge level was poor. The information on the respondent's knowledge on ever heard about Pap smear test from anyone shows that among all the respondents, $42 \%$ have heard about Pap smear test whereas rest $58 \%$ of respondents never heard about a Pap smear test. Among those who have heard about the Pap smear test, $21 \%$ of respondents have heard about the test from friends, $30 \%$ have heard from medical doctor or nurses, $21 \%$ of respondents have heard from Community Health Service Workers and the rest $28 \%$ have heard about it from other sources.

$6 \%$ of respondents told that cervical cancer cannot be prevented, $23 \%$ told that it can be prevented by screening, $13 \%$ told that vaccination is the method of preventing $\mathrm{CC}, 16 \%$ responded that delay early sexual debut helps prevent cervical cancer, $7 \%$ told that avoiding having multi-partner helps prevent cervical cancer, $4 \%$ responded that limiting the number of children can be helpful for prevention of cervical cancer, $2 \%$ told that avoiding tobacco can help prevent cervical cancer and the rest $29 \%$ said that they didn't know the prevention methods of cervical cancer.

The association between socio-demographic factors and knowledge of cervical cancer among undergraduate university students. The findings show that the respondent's years of study are significantly corelated with the knowledge level of the respondents regarding cervical cancer. The findings also show that the respondent's age and marital status have no significant association with the knowledge level of the respondents regarding cervical cancer.

\section{CONCLUSION}

In conclusion, although participants in this study did not report engaging in some risk factors associated with cervical cancer, they had poor knowledge of etiology, mode of transmission, symptoms, prevention methods, and different risk factors that increase the progression of cervical cancer as well as poor perception towards the chance of acquiring the disease. Furthermore, using TV and Radio and having information on STI were the determinants of knowledge on cervical cancer. The result obtained in this study indicates how useful it will be to establish health education programs to increase students' awareness and knowledge about cervical cancer. Health education interventions are needed to improve the understanding of the factors that increases the risk and the prevention methods of cervical cancer in youth women to prevent before women engage in risky behaviors to develop healthy behavior and decrease the incidence of the disease. Governments and nongovernmental organizations should work in collaboration in improving knowledge of cervical cancer and screening among youth women.

\section{RECOMMENDATION}

- Health education interventions are needed to improve the understanding of the factors that increases the risk and the prevention methods of cervical cancer.

- Governments and non-governmental organizations should collaborate in improving knowledge of cervical cancer and screening among youth women.

- $\quad$ This type of study should be conducted with a larger sample size to generalize the findings. 


\section{REFERENCES}

1. WHO/ICO Information Centre on HPV and Cervical Cancer (HPV Information Centre). (2009). Human Papillomavirus and Related Cancers in Africa. Summary Report.

2. World Health Organization. (2002). Cervical Cancer Screening in Developing Countries. Report of a WHO Consultation. Geneva: WHO.

3. Parkin, D.M., Bray, F., Ferlay, J., Pisani, P. (2005). Global cancer statistics. CA Cancer J Clin.

4. Sankaranarayanan, R., Budukh, A.M., Rajkumar, R. (2001). Effective screening programs for cervical cancer in low- and middle-income developing countries. Bull World Health Organ.

5. Gakidou, E., Nordhagen, S., Obermeyer, Z. (2008). Coverage of cervical cancer screening in 57 countries: Low average levels and large inequalities. Pub Med.

6. Denny, L. (2006). Prevention of cervical cancer. In: Ijumba P, Padarath A, editors. South African Health Review. Durban: Health Systems Trust.

7. Jamal, A., Siegel, R., Ward, E., Murray, T., Xu, J., Smigal, C. (2006). Cancer statistics: CA Cancer J Clin.

8. Moodley, J., Kawonga, M., Bradley, J., Hoffman, M. (2006). Challenges in implementing a cervical screening program in South Africa. Cancer Detect Prev.

9. GLOBOCAN. (2008). Cancer incidence and mortality worldwide.

10. Blair, A.R., Casas, C.M. (2009). Gynecologic cancers. Prim Care.

11. Hughes, C. (2009). Cervical cancer: Prevention, diagnosis, treatment and nursing care. Nurs Stand.

12. Plus News. (2007). Global HIV/AIDS news and Analysis. South Africa: Cervical cancer vaccine offers distant hope.

13. Avert. (2008). South Africa: HIV and AIDS Statistics.

14. Mqoqi, N., Kellett, P., Sitas, F., Jula, M. (2004). Incidence of histologically Diagnosed cancer in South Africa, 1998 - 1999. Johannesburg: The National Cancer Registry of South Africa. National Health Laboratory Service.

15. Abouzahr, C., Wardlaw, T. (2000). Maternal mortality: Estimates developed by WHO, UNICEF and UNFPA.

16. Ferlay, J, Bray, F., Pissani, P., Parkin, D.M. (2004). GLOBOCAN 2002: Cancer Incidence, Mortality and Prevalence Worldwide, IARC Cancer Base No. 5, version 2.0. Lyon, France: IARC Press.

17. Fonn, S., Bloch, B., Mabina, M., Carpenter, S., Cronje, H., Maise, C. (2002). Prevalence of precancerous lesions and cervical cancer in South Africa-a multicenter study. S Afr Med J.

18. Hoque, M., Hoque, E., Kadar, S.B. (2008). Evaluation of cervical cancer screening program at a rural community of South Africa. East Afr $J$ Public Health.
19. Ayinde, O.A., Omigbodun, A.O., Ilesanmi, A.O. (2004). Awareness of cervical cancer, Papanicolau's smear and its utilization among female undergraduates in Ibadan. Afr J Reprod Health.

20. The Kaiser Family Foundation. National Survey of Public Knowledge of HPV, the Human Papillomavirus.

21. Abdul-Aziz, M. (2012). Knowledge, attitude and practice towards cervical cancer among reproductive health clients at the University of Science and Technology Hospital-Sana'a in Yemen. Yemeni J Med Sci.

22. Abiodun, O.A., Fatungase, O.K., Awosile, J.O. (2013). An assessment of women's awareness and knowledge about cervical cancer and screening and the barriers to cervical screening in Ogun State. IOSR J Dental Med Sci.

23. Abudukadeer, A., Azam, S., Mutailipu, A. (2015). Knowledge and attitude of Uyghur women in Xinjiang province of China related to the prevention and early detection of cervical cancer. World J Surg Oncol.

24. Ayinde, O.A., Omigbodun, A.O., Ilesanmi, A.O. (2004). Awareness of cervical cancer, Papanicolaou's smear and its utilization among female undergraduates in Ibadan. Afr J Reprod Health.

25. Bansal, Agam, B., Pakhare, Abhijit, P., Kapoor, N., Mehrotra, Ragini, K.A. (2015). Knowledge, attitude, and practices related to cervical cancer among adult women: A hospital-based crosssectional study. J Nat Sci Biol Med.

26. Basu, P., Hassan, S., Fileeshia, F. (2014). Knowledge, attitude and practices of women in Maldives related to the risk factors, prevention and early detection of cervical cancer. Asian Pac J Cancer Prev.

27. Bruni, L., Barrionuevo-Rosas, L., Albero, G. (2016). Human Papillomavirus and related diseases report. ICO Information Centre on HPV and Cancer (HPV Information Centre).

28. Dhendup, T., Tshering, P. (2014). Cervical cancer knowledge and screening behaviors among female university graduates of year 2012 attending national graduate orientation program, Bhutan. BMC Women's Health.

29. Envuladu, E.A., Ohize, V.A., Agbo, H.A., Lar, L.A, Z.A. (2013). Awareness and uptake of papanicoloau smear screening among students of a higher institution in Jos, Nigeria. Jos J Med.

30. Ethiopia Ministry of Health. (2015). Guideline for cervical cancer prevention and control in Ethiopia. Getahun F, Mazengia Fekadu AM, Birhanu Z.

31. Comprehensive knowledge about cervical cancer is low among women in Northwest Ethiopia. BMC Cancer.

32. Hoque, E., Hoque, M. (2009). Knowledge of and attitude towards cervical cancer among female 
university students in South Africa. South Afr J Epidemiol Infect.

33. Hoque, M.E. (2010). Cervical cancer awareness and preventive behaviour among female university students in South Africa. Asian Pac JCancer Prev.

34. ICO Information Centre on HPV and cancer. (2015). Human papillomavirus and related diseases report. Barcelona.

35. Isa, I.A., Ibukun, G.O., Olugbenga, M.K. (2013). Cervical cancer screening among female undergraduates and staff in the Niger delta region of Nigeria. Open J Obstet Gynecol.

36. Muliira, J.K., Kisaakye, E., Kizza, I., Betty, S.R.R (2011). Perceived cervical cancer risk, knowledge and preventive practices. Afr J Midwifery Women's Health.

37. Rates, G.I. (2009). Global and regional statistics: Cervical cancer and HPV.
38. Roy, S., Devleena, M.T., Chaudhuri, P., Lahiri, D.B.J. (2011). Addition of gemcitabine to standard therapy in locally advanced cervical cancer: A randomized comparative study. Indian J Med Pediatric Oncol.

39. Shin, H.R., Franceschi, S., Vaccarella, S. (2004). Prevalence and determinants of genital infection with papillomavirus, in female and male university students in Busan, South Korea. J Infect Dis.

40. Stuart, W., Weinstock, H., Berman, S. (2000). Sexually transmitted diseases among American youth: incidence and prevalence estimates. Int Perspective Sex Report Health.

41. World Health Organization. (2013). Comprehensive cervical cancer prevention and control: a healthier future for girls and women. World Health Organization. Geneva. 